\title{
Improved price index for condominiums
}

\author{
by \\ Han-Suck Song ${ }^{\mathrm{a}}$ and Mats Wilhelmsson ${ }^{\mathrm{b}}$ \\ a) Department of Real Estate and Construction Management, \\ Royal Institute of Technology (KTH), Stockholm, Sweden \\ han-suck.song@abe.kth.se \\ b) Centre for Banking and Finance (CEFIN), \\ Royal Institute of Technology (KTH), Stockholm, Sweden \\ matswil@kth.se
}

\begin{abstract}
:
This paper proposes a price index construction methodology that can increase the quality of price index data for condominiums in Sweden. Currently, officially published market price indexes for condominiums and houses in Sweden suffer from a number of shortcomings. Notably they do not control for quality, or they are based on dates when transfer of ownership of the home occurs, and not the contract date. We develop a new price index that both controls for quality and reflect most recent price levels and changes. With access to a unique database we estimate alternative hedonic price indexes, and compare them both between themselves, as well as with arithmetic mean and median price indexes. However, there is a trade-off between control of quality, access to the most recent transactions, and market coverage on one hand, and ease of construction on the other hand.
\end{abstract}

Keywords: Apartment, price index, moving window regression, spatial econometrics, contract date

Acknowledgement: Valueguard Index Sweden is highly acknowledged for the financial support and Mäklarstatistik for the data. 
One of the financial system's key tasks is to provide the market's many stakeholders with accurate information. In so called efficient housing markets, prices of individual homes should constitute effective carriers of information: the price of the sale of the dwelling should accurately reflect its inherent value and attributes and fully reflect all available information. This means that residential buyers and sellers quickly and flawlessly will process and react to new information.

Housing price indexes are important for several reasons. For instance, the indexes are used as macroeconomic indicators, as input to the calculation of CPI, and calculation of household wealth as well as analysis of lenders exposure to insolvency and foreclosures, assessment of risk of a housing price bubble, and as an important input in monetary policy decisions (see e.g. Diewert, 2007). Moreover, several scholars suggest that home owners and other actors can achieve more efficient asset portfolios and better possibilities to manage housing risks with options and futures markets for housing (Case et al., 1993; Deng and Quigley, 2008; Englund et al., 2002). However the integrity of markets for home price index derivatives depends on reliable indexes that can accurately and in real time track the underlying housing markets (Clapham et al., 2006; Deng and Quigley, 2008).

The objective of this article is to contribute to the literature on the production of reliable apartment price indexes. The main contribution is, first, that we utilize a unique geographically coded apartment dataset with arms-length transactions in Stockholm, Sweden. Second, we compare an estimated aggregated hedonic price index, which assumes that the underlying true population model of price determinants does not change over time, with estimated moving window regression indexes, in order to test whether the assumption of constant implicit prices over time is reasonable or not. Third, we test for spatial dependency and implement spatial models into the aggregated hedonic approach. Fourth, we use price information that is related to contract dates (i.e. the date when the contract was signed) and not the transaction dates (i.e. when the ownership or deed is transferred from the seller to the buyer). Finally, we evaluate the aggregated hedonic approach with the moving window approach using the root mean squared error of an out-of-sample prediction.

The paper is organized as follow. In section two, the methodology including a literature review is presented. We presents the data and the empirical analysis in section three, and the paper end with conclusions in section four. 


\section{Apartment Price Indexes}

Essentially three different types of transaction-based methods can be used in the study of apartment price fluctuations. ${ }^{1}$ The first one is a simple average price index (using arithmetic mean or median, sales prices), the second is the so-called repeated-sales price index (see Bailey et al. 1963, and Case and Schiller, 1987), and the third is the hedonic price index (see e.g. recent articles by Shimizu and Nishimura, 2007, and Wilhelmsson, 2009). Mark and Goldberg (1984) discusses eleven alternative housing price indexes based on mainly these three major categories of methods to construct home price indexes.

A price index using median or arithmetic mean of sale prices does not attempt to control for different types of homes sold over time, hence, it is of no use in the study of apartment price fluctuations (see Case and Shiller, 1987). Moreover, Meese and Wallace (1997) results indicate that the repeated-sales method has some severe problems in that it is very sensitive to influential observations, sample selection bias, and that the implicit assumption about parameter constancy over time is violated. Thus, repeated-sales method index has only limited use in the study of regional price fluctuation.

Gatzlaff and Haurin (1997) observe that transactions, and especially multiple transactions, may have non-random statistical properties, which will bias the estimate of the index. Their empirical analysis concludes that there is "evidence that changing economic conditions affect the statistical composition of the sample of sold homes". The potential presence of sample selection bias may be more severe when it comes to the repeated-sales method. For a further discussion about the repeated-sales method, see e.g. Chau et al. (2005).

Recently, Bourassa et al. (2006) proposed a simple alternative price index method, which they call sale price appraisal ratio method (SPAR). The method is a combination of transactionbased and appraisal-based methods in that it forms a ratio between the transaction price and the appraised value. The average ratio is used to construct the index. Hence, it is better than a median or average price index in that it controls for quality. The authors claim that the method produce indexes similar to the quality-adjusted repeated-sales indexes in New Zealand. The main drawback of the method is that it needs frequent updates of the appraisals with the help of presumably a hedonic regression. Therefore Shi et al. (2009) further discuss the possibility of

\footnotetext{
${ }^{1}$ Another type of methods is appraisal-based indices that can be used when the market information is limited. However, our apartment prices index will be based on transaction prices and not appraisal values.
} 
producing a monthly house price index in New Zealand using the SPAR method. They compare the SPAR method with the repeat sales price as well as median indices, and conclude that further empirical research is needed in order to benchmark and compare the different alternative indexing methods.

The hedonic model has been widely used in USA. In UK, the Halifax Building Society has constructed a quarterly price index in 12 different regions. They base their index on the hedonic regression model. Their indexes are available for new houses and existing houses, but also for first-time and former owner buyers (see Hoesli and MacGregor, 2000). The study by Meese and Wallace (1997) suggests that the hedonic method is better suited for construction of price indices, and Englund (2009) put it like this: "In many European countries, there is detailed public information about house characteristics, making it possible to estimate good hedonic indexes. In the U.S., on the other hand, only sales prices are available, making repeat-sales indexes the only viable alternative". A drawback with the hedonic regression model is omitted variable bias (see, for example, Hoesli and MacGregor, 2000). Based on publicly available data for the apartment market in Paris, Maurer et al (2004) calculate a transaction-based price index for apartments in Paris.

Clapham et al. (2006) investigate the stability of the index for owner-occupied housing, the socalled "revision volatility". Upon an extension (updating of the index with new information) of an index series, they argue that the usefulness of the property price index depends on the stability of the index. Their conclusion is that indices based on the hedonic regression model are "substantially more stable than repeat-sales indexes and are not prone to the systematic downward revision found in the repeat-sales indexes". This is also something that Wang and Zorn (1997) recognize. They argue that it is not a theoretical problem, but a practical one. The reason why the estimates are not stable is that the sample changes, as more periods are included.

\section{The Aggregated Hedonic Apartment Price Index with Time Dummies}

By using the data collected, we construct a cross-sectional and time-series hedonic equation of cooperative apartment prices in the county of Stockholm, Sweden. A hedonic equation is a regression of prices against attributes that determine these prices and time. The interpretation of regression coefficients is as estimates of the implicit (hedonic) prices of these attributes, hence, the willingness-to-pay for the attribute in question (see Rosen, 1974). The method has a long tradition. Recent articles are, for example, Kestens et al. (2006) and Wilhelmsson (2008a, $2008 \mathrm{~b}$ and 2009). Following the literature, the hedonic price equation is equal to

$$
Y_{i, t}=\beta_{0}+X_{i, t} \beta_{1}+T D_{t} \beta_{2, t}+\varepsilon_{i, t} \quad i=1, \ldots, \mathrm{N} \text { and } t=1, \ldots, \mathrm{T}
$$


where $Y$ is the dependent variable transaction price (normally in $\log$ form), $\beta_{l}$ is a vector of parameters (regression coefficients) associated with exogenous explanatory variables, $X$. The stochastic term $\varepsilon$ is assumed to have a constant variance and normal distribution. Normally, we implicitly assume that all relevant attributes are included in the matrix $X$ : in other words, no omitted variable bias problem exists. We can decompose $X$ into, for example, structural apartment and property attributes, as well as neighborhood attributes. The variable $T D$ with subscript $t$ is a dummy variable for each period and equal one for period $t$ and zero otherwise (in this case month). $N$ is equal to the number of observations and $T$ is equal to the number of periods.

\section{Interpretation of dummy variables in a semi-logarithmic equation}

We estimate hedonic price equations in which the dependent variable price appears in logarithmic form, with a number of monthly time dummy variables as independent variables. Therefore the parameter estimates concerning the dummy variables have a percentage interpretation: when multiplied by 100 , the estimated parameter on a dummy variable is interpreted as the approximate percentage change in the dependent variable (Wooldridge, 2006). In a hedonic price index application, the exponential of the estimated time dummy parameters might therefore be interpreted as the approximate rate of growth in the mean price with respect to the mean price at the beginning (see Hansen, 2006).

When the estimated dummy parameters indicates a large change in the dependent variable, Halvorsen and Palmquist (1980) suggest that the exact percentage difference should be computed as $100 *[\exp (b)-1]$ (see also Wooldridge, 2006).

However, Kennedy (1981) argues that the correct expression is equal to $p=[\exp (b-1 / 2 \mathrm{~V}(b))-1] * 100$ (see also Goldberger, 1968), where $\mathrm{V}(b)$ is an estimate of the variance of $b$. Giles (1982) argues that from a finite sample bias view, the latter is preferred. Recently, Garderen and Shah (2002) derive a simple approximation of the variance to Kennedy's estimator of the percentage change as in Eq. 2 below. ${ }^{2}$

$$
V(p)=100^{2} \exp \{2 b\}[\exp \{-V(b)\}-\exp \{-2 V(b)\}]
$$

\footnotetext{
${ }^{2}$ The null hypothesis that $b_{t}-b_{t-1}=0$ is tested using $t=\frac{b_{t}-b_{t-1}}{s e\left(b_{t}-b_{t-1}\right)}$, where se is standard deviation.
} 
Below we apply the Kennedy (1981) formula when we predict the monthly index numbers. However, the differences in index numbers obtained using the Kennedy (1981), and Halvorsen and Palmquist (1980) approaches respectively, are basically non-existent in our applications.

\section{Parameter heterogeneity}

In the conventional hedonic framework described above, we first estimate a single pooled regression for all time periods in our sample, and then construct a monthly price index directly from the estimated time dummy coefficients. A drawback of this method is that it implicitly assumes that the hedonic prices of the attributes are time-invariant, which has led to criticism (see e.g. Hill and Melser, 2008; Pakes, 2003) arguing that it is not a reasonable assumption. However, as Clapham et al. (2006) argue, wrongly assumed constant implicit prices over time may not necessarily generate a biased property index.

In this article we apply a variant of moving window regression in order to test if a bias is present. Moving window regression (MWR) has been used in order to incorporate spatial dependency by using sliding neighborhoods (see Páez and Long, 2008). Our MWR approach can instead be conceptualized as sliding time spans. Interestingly, Palmquist (1980) presents a method that uses pairs of adjacent years in a multiple hedonic equation framework with time dummies to develop an index. Although Palmquist concludes that the use of this method is a valid approach, the computed index was not significantly different compared to an index based on a single aggregated hedonic price equation. In some sense, Meese and Wallace (2003) use a nonparametric version of the moving window regression techniques, namely locally weighted regression (LWR).

The advantage with MWR is that we allow that the hedonic prices can change over time, while still using data for a longer period. The price index is obtained directly from the estimated time dummy coefficients. When each moving window spans over 12 months, the regression coefficients can be obtained as follows:

$$
\begin{array}{ll}
Y_{i, t}=\beta_{0}+X_{i, t} \beta_{1}+T D_{t} \beta_{2, t}+\varepsilon_{i, t} & \mathrm{i}=\mathrm{n}_{1}, \ldots . \mathrm{n}_{12} \text { and } \mathrm{t}=1, \ldots, 12 \\
Y_{i, t}=\beta_{0}+X_{i, t} \beta_{1}+T D_{t} \beta_{2, t}+\varepsilon_{i, t} & \mathrm{i}=\mathrm{n}_{2}, \ldots, \mathrm{n}_{13} \text { and } \mathrm{t}=2, \ldots, 13 \\
\cdot & \\
\cdot & \\
Y_{i, t}=\beta_{0}+X_{i, t} \beta_{1}+T D_{t} \beta_{2, t}+\varepsilon_{i, t} & \mathrm{i}=\mathrm{n}_{T-11}, \ldots, \mathrm{n}_{T} \text { and } \mathrm{t}=\mathrm{T}-11, \ldots, \mathrm{T}
\end{array}
$$

The first model uses $n_{1}$ transactions from the first 12 periods and. The second hedonic model will use $n_{2}$ observations from the second time window (period 2 to period 13). That is, there 
will be an overlap of 11 periods between the first hedonic model and the second in the MWR model structure. Altogether, $T-11$ hedonic models will be estimated if the window size is equal to 12 periods, where $T$ is the total number of all periods in the sample.

\section{Laspeyres and Paasche index}

An alternative method is to apply the approach Meese and Wallace (1997) use in order to control for the fact that the implicit prices concerning the property attributes might vary in time (see also Crone and Voith, 1992). First, the price coefficients for structural and neighborhood attributes are estimated for each temporal cross-section. Since a new regression equation is estimated for, this method is more likely to suffer from small samples than the aggregated hedonic method. By choosing a "standard home" based on either the initial (base period) or final period average home characteristics, Laspeyres or Paasche indexes can be computed. In other words, these indexes "value" the average initial or final period home respectively, for each period using that period's implicit prices (see Mark and Goldberg, 1984). Meese and Wallace (1997) and Clapham et al. (2006) both construct a Fischer Ideal index, which is the geometric average of the Laspeyres and Paasche indexes.

We have not used this methodology, since the number of observations is limited in each month (that is the length of our periods). Instead we use the above described moving window regression without any weights, combined with initial and last period average home characteristics respectively as quantity weights when we predict the index figures for each period (a moving windows analogy to Paasche and Laspeyres indexes).

\section{Omitted variables and spatial dependency}

As stated, one of the major drawbacks with the hedonic method is omitted variables bias. If an unobservable characteristic increases over time, it can be mistakenly taken as a price appreciation when it is actually the result of the change in characteristics. If the omitted variable is positively correlated with the time dummies and with price, our estimated parameters concerning time will be upwardly biased. If the omitted variable is negatively related to price, the bias will be negative (see Wooldridge, 2006).

Omitted variables can also cause spatial dependency. It means that observations at one location depend on other observations at a number of other locations. Spatial dependency bears some resemblance to temporal dependency (see Wilhelmsson, 2002a). A general spatial model incorporates a spatial structure into both the dependent variable and the error term (see Anselin, 1988). 


$$
\begin{aligned}
& Y_{i, t}=\beta_{0}+\rho W Y_{i, t}+X_{i, t} \beta_{1}+T D_{t} \beta_{2, t}+\varepsilon_{i, t} \\
& \varepsilon_{i, t}=\lambda W Y_{i, t}+\eta_{i, t}
\end{aligned}
$$

The parameter $\rho$ is the coefficient of the spatially lagged dependent variable and the parameter $\lambda$ is the coefficient of the spatial autoregressive structure of the error. $W$ is equal to the spatial weight matrix. The special structure is a spatial weight matrix that is defined by how much a nearby (in space) observation should influence the averaging procedure. The spatial weight matrix is usually defined by inverse square distance between observations or by the nearest neighbors (Dubin, 1998). We will use the latter definition. If parameter $\rho$ is equal to zero, a spatial error model (SEM) is estimated and if $\lambda$ is equal to zero, a spatial autoregressive (SAR) model is estimated.

Can and Magbolugbe (1997) investigate spatial dependency and property price index construction. They start their discussion with the hedonic price model and compare it with a hedonic spatial model. They conclude that the inclusion of a spatial structure is important for both parameter estimates and statistical inference. Wilhelmsson's (2002a) results indicate, among other things, that property data is highly spatially dependent. Accounting for spatial effects, with the inclusion of distance and sub-market dummies, does not mean that the hypothesis of no spatial autocorrelation can be rejected. However, it is an empirical question if spatial dependency bias the parameter estimates concerning the price index. 


\section{The Empirical Analysis}

\section{The empirical hedonic regression model}

The dependent variable in the hedonic price equation is observed arm-length transaction prices of cooperative apartments. As apartment attributes, we have used the size of the apartment together with number of rooms. Both of them are hypothesized to have a positive effect on price. Besides the size, we have also used the monthly fee to the management of the house. This variable is supposed to have a negative effect on price. Another apartment characteristic is whether the apartment has a balcony or not. Finally, we have included three variables indicating where in the building the apartment is located. The first is the floor level and the other two are dummy variables indicating if the apartment is on floor 1 or the top floor. Our hypotheses are that floor one is associated with a discount and the top floor (with a possible view) with a premium.

Only three property attributes are going to be used in this application, namely the age of the property, the height of the property and whether the property have an elevator or not. The age of the property is a proxy for the quality of the property and the apartment, but instead of using a continuous variable, we have constructed seven different dummy variables. Our hypothesis is that relatively new and very old apartments have the highest prices, while the apartments built during the "Million programme" have the prices lowest.

Table 1. Specification of dummy variables indicating which time period the properties in which the apartments are located was built.

\begin{tabular}{l|l|l}
\hline Dummy variable & Year of construction & Explanation \\
\hline Byear1 & Before 1900 & \\
Byear2 & $1900-1939$ & Before Second War II \\
Byear3 & $1940-1959$ & Post-war period \\
Byear4 & $1960-1975$ & The "Million programme" era \\
Byear5 & $1976-1990$ & Period with high construction subsidies \\
$\begin{array}{l}\text { Byear6 (Base variable } \\
\text { in regressions below) }\end{array}$ & After 1990 & Abolishment of the subsidy system \\
New & $\begin{array}{l}\text { If year of construction } \\
\text { = year of sale }\end{array}$ & \\
\hline
\end{tabular}

The information about the neighbourhood characteristics is scarce. By estimating the distance to the centre of the city, a price gradient can be estimated. Naturally, distance is supposed to 
have a negative effect on price. As in Söderberg and Janssen (2001), as well as in Kryvobokow and Wilhelmsson (2007), we analyse whether the CBD accessibility affects the price differently in different geographical directions. Thus, besides distance, we have also divided the city into four quadrants (northwest, northeast, southwest and southeast). Three of these have been included in the model. Moreover, we have also tested if the price gradient is different in different geographical directions. In order to reduce spatial dependency further, the last attributes included are longitude and latitude coordinates (see e.g. Wilhelmsson, 2009, and Galster et al, 2004). Furthermore, the hedonic model includes 28 dummy variables concerning sub-markets. The submarkets are defined as the administrative parish. The parish variables together with distance variables are included as to reduce omitted variables bias and to mitigate spatial dependence. Besides the apartment and property characteristics, as well as the neighborhood attributes, 48 time dummies have been included in the hedonic price equation.

\section{The data}

To be able to construct a monthly price index concerning apartments we have based the empirical analysis in this paper on cross-sectional time-series data that includes arms-length transactions of condominiums in Stockholm, Sweden. The data covers a time span from January 2005 to June 2009 and consists of 34,059 transactions of condominiums. ${ }^{3}$

In order to provide different actors with information about the most recent price changes, the periodical index numbers should reflect the price levels prevailing in each time period. However, public indexes and academic studies that use Swedish data on single-family homes (see e.g. Wilhelmsson, 2009; Englund et al, 1998; and Clapham et al, 2006) are commonly based on transaction dates instead of contract dates. ${ }^{4}$ This might cause indexes to suffer from time lags, especially if the average number of days elapsing between contract dates and transaction dates is large. The average number of days between the contract date and transfer date amounts to 55 days in the sample. Consequently, a major strength of this article is that we use the contract date instead of the transfer date when we compute the different indexes. Indeed, this article is - as far as we know - the first study of home price index construction for the

\footnotetext{
${ }^{3}$ The total number of transaction is 41,818 but the data have been "cleaned" by excluding apartments that have a price above 10,000,000 SEK, living area above 227 square meters, price per square meter above 80,000 SEK, and apartments with more than 9 rooms, as well as built before the year 1635 .

${ }^{4}$ This problem occurs since it is transfer dates of house sales that are recorded in Swedish official registers. The transfer date is the date when the deed is transferred from the seller to the buyer, and normally, it is the date when the buyer takes a mortgage and moves into the home. However, this date is in not the same as when the contract was actually signed. This problem is also present in the US.
} 
Swedish market that uses contract dates instead of transfer dates. Figure 1 below displays the number of monthly transactions and price per square meter.

Figure 1. Number of transactions per month and median price per square meter.

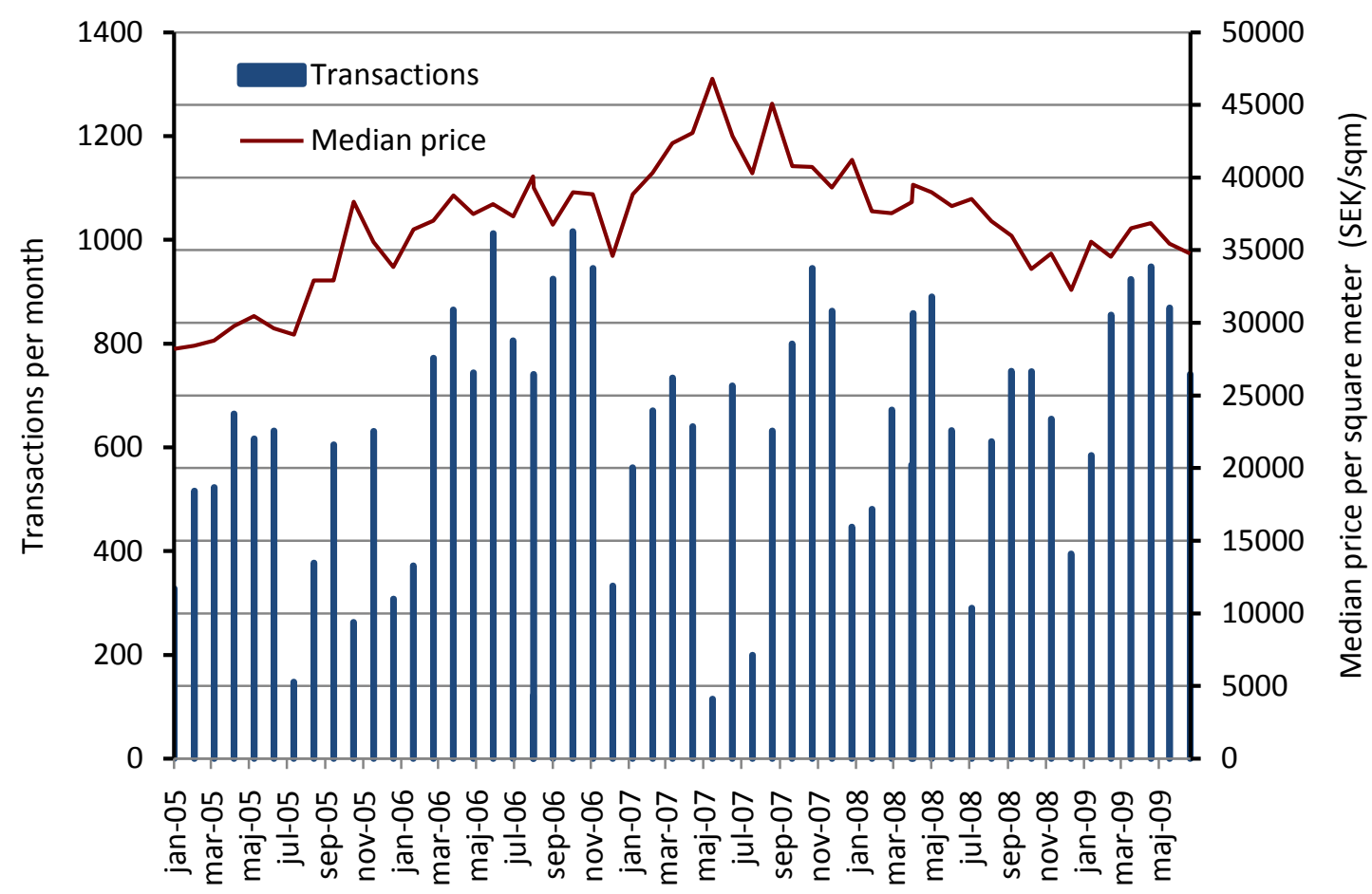

The average monthly number of sales is about 630 . The number of sales has always gone down during the summer months and we can observe the highest number of transaction in the fall (except in the year 2008 during the financial meltdown). The median sales prices have increased from slightly more than 28,000 SEK per square meter to almost 35,000. However, the highest median price $(47,000 \mathrm{SEK} / \mathrm{sqm})$ can be observed in May $2007 .{ }^{5}$ The correlation between number of transactions and price per square meter is low. The descriptive statistics are shown in the table below.

\footnotetext{
${ }^{5}$ However, the number of sales that month was exceptional small, only 115.
} 
Table 2. Descriptive statistics for cooperative apartment transactions from January 2005 to June 2009, Stockholm city. ${ }^{6}$

\begin{tabular}{|c|c|c|c|c|c|}
\hline Variable & Definition & Average & $\begin{array}{l}\text { Standard } \\
\text { deviation }\end{array}$ & Min & $\operatorname{Max}$ \\
\hline Price & SEK & $2,124,290$ & $1,287,835$ & 505,000 & $6,975,000$ \\
\hline Living area & Square meters & 60.20 & 22.95 & 22 & 149 \\
\hline Rooms & Number of rooms & 2.24 & 0.95 & 1 & 6 \\
\hline Fee & Monthly fee: SEK & 2,978 & 1216 & 1 & 7993 \\
\hline Balc & Dummy: Balcony & 0.13 & 0.33 & 0 & 1 \\
\hline First & Dummy: First floor & 0.20 & 0.40 & 0 & 1 \\
\hline Top & Dummy: Top floor & 0.30 & 0.46 & 0 & 1 \\
\hline Byear1 & Dummy: Before 1900 & 0.05 & 0.21 & 0 & 1 \\
\hline Byear2 & Dummy: 1900-1939 & 0.38 & 0.49 & 0 & 1 \\
\hline Byear3 & Dummy: 1940-1959 & 0.24 & 0.43 & 0 & 1 \\
\hline Byear4 & Dummy: 1960-1975 & 0.07 & 0.25 & 0 & 1 \\
\hline Byear5 & Dummy: 1976-1990 & 0.05 & 0.22 & 0 & 1 \\
\hline Byear6 & Dummy: After 1990 & 0.21 & 0.41 & 0 & 1 \\
\hline New & Dummy: New building & 0.02 & 0.12 & 0 & 1 \\
\hline Elev & Dummy: Elevator & 0.57 & 0.49 & 0 & 1 \\
\hline Distance & Meters to city & 3,970 & 2,780 & 45 & 12,570 \\
\hline $\mathrm{NE}$ & Dummy: Northeast & 0.17 & 0.38 & 0 & 1 \\
\hline NW & Dummy: Northwest & 0.31 & 0.46 & 0 & 1 \\
\hline SW & Dummy: Southwest & 0.21 & 0.41 & 0 & 1 \\
\hline $\begin{array}{l}\text { No. of } \\
\text { observations }\end{array}$ & & 34,059 & & & \\
\hline
\end{tabular}

The average (arithmetic mean) price is slightly higher than 2,120,000 SEK, while the median price is $1,800,000 \mathrm{SEK}^{7}$ The standard deviation of the price is high. The number of square meter living area is around 60 square meters and the average apartment consists of approximately 2.2 rooms. The fee paid for maintenance is about 3,000 SEK per month. Almost 20 percent of the apartments are located on the first floor and almost 30 percent on the top floor. Around 13 percent of the apartments have balcony.

\footnotetext{
${ }^{6}$ Concerning the variables elevator and balcony data is missing. If information is missing, we have assumed that the apartment does not have a balcony and that the property does not have an elevator.

${ }^{7}$ The skewness of 1.3 also indicates that the distribution of prices is positively skewed.
} 
Only 2 percent of the apartments are new (sales year equal to construction year), and around 23 percent are constructed after 1990 (a period when construction subsidies started to diminish). Most of the apartments are constructed before the Second World War. Around 12 percent of the transacted apartments are located in buildings that have been produced from 1960 to 1990. Almost 60 percent of the apartments are situated in properties with elevator.

By using the geographical codes (coordinates), we estimate the distance from the apartment to the "centre of the city". However we do not have access to the exact location of the centre. Instead we estimate the median coordinates in order to approximate a proxy for city centre. The average distance between the apartments and the centre of Stockholm is almost 4 kilometers $(\mathrm{km})$, but the standard deviation is high $(2.7 \mathrm{~km})$.

\section{Hedonic price index with constant implicit prices over time}

The benchmark model uses all the attributes described earlier. Economic theory, however, fails to indicate any particular functional form for the (hedonic) price equation. Halvorsen and Pollakowski (1981), for example, use a Box-Cox transformation to find the best fitting form. We have used the same transformation and our result indicates that a log-linear form is preferred. ${ }^{8}$ Hence, we can interpret the parameters as elasticities. Moreover, we estimate one hedonic price equation for the whole period, thus, implicitly assuming that the implicit prices concerning the apartment and property characteristics are constant over time. This assumption will later be relaxed in the moving window regression. The results are exhibited in the table below.

\footnotetext{
${ }^{8}$ We have tested a model with all variables strictly positive. The result indicates that we cannot reject the hypothesis that both lambda and theta is equal to zero, that is to say, a log-linear model is preferred. We have also tested a model where the explanatory variables are not strictly positive (i.e. we have included the dummy variables) and tested whether the dependent variable should be transformed or not. The result clearly suggests that price should be transformed (natural logarithm).
} 
Table 3. Regression results for aggregated hedonic equation (dependent variable=natural logarithm of price).

\begin{tabular}{l|rrr}
\hline Variable & Coefficient & t-value & VIF \\
\hline Constant & -96.441 & -5.40 & \\
Living area (sqm) & 0.887 & 90.54 & 6.01 \\
Rooms & 0.129 & 27.37 & 4.59 \\
Fee (SEK/month) & -0.203 & -17.39 & 3.04 \\
Balc & 0.0165 & 4.45 & 1.46 \\
First & -0.007 & -1.95 & 2.05 \\
Top & 0.020 & 6.07 & 2.06 \\
Byear1 & 0.052 & 10.21 & 1.50 \\
Byear2 & 0.015 & 4.43 & 2.60 \\
Byear3 & -0.018 & -4.34 & 2.30 \\
Byear4 & -0.156 & -24.17 & 1.43 \\
Byear5 & -0.151 & -19.97 & 1.47 \\
New & 0.052 & 6.58 & 1.13 \\
Elev*Floor & 0.009 & 5.09 & 10.96 \\
Elev & -0.038 & -8.34 & 4.68 \\
Dist & -0.214 & -30.59 & 21.77 \\
\hline No. of observations & 34,059 & & \\
$\mathrm{R}^{2}$-adj & 0.86 & & \\
\hline Not All cont
\end{tabular}

Note: All continuous variables are transformed (natural logarithm). The coefficient estimates concerning the variables $\mathrm{X}$ - and $\mathrm{Y}$ coordinates, NE, NW, and SW, as well as the interaction variables between the distance variable and the NE, NW, and SW variables, are not shown in the table. For many transactions we do not have access to information about elevator, balcony, floor level and number of floors. As an alternative to dropping the observations from the analysis, we have included a number of dummy variables that indicate when we lack such information. The coefficient estimates concerning the time and sub-markets dummy variables are not shown in the table. Robust variance estimates.

Almost 86 percent of the variation in apartment prices across space and over time is explained by the explanatory variables. The explanation power is considered high. All estimated parameters have expected sign, except for elevator. However when we add an interaction variable that combines the elevator variable with number of floors, we can conclude that elevator has a positive effect on prices for apartments located on floor four and above. If living area increases by 1 percent, apartment prices is expected to increase on average by almost 0.9 percent. On the other hand, if the monthly fee is 1 percent higher, the prices will on average be 0.2 percent lower. An apartment on the top floor is on average 2 percent more expensive than non top floor apartments.

The effect of quality, indicated by the building year dummy variables (Byear1-Byear5), is compared against the base group dummy variable Byear6 which incorporate properties that are built after 1990 (see table 1). Apartments built in the 1960s' to the 1980s' (Byear4) are shown to have the lowest price. For example, apartments constructed during the "Million programme" 
are sold with about 14 percent discount ${ }^{9}$. The prices of new apartments (defined as properties that are built the same year as the year the apartment was sold) are estimated to be on average 5 percent higher. Distance away from the center has a negative impact on prices.

To investigate the existence of multicollinearity, we have computed variance inflationary factors (VIF) for individual coefficients. The principle that VIF in excess of 10 suggests multicollinearity is usually used in the literature, see e.g. Seiler et al. (2001) and Des Rosiers et al. (2001). The reason for why the distance from centre variable has a high VIF is of course the inclusion of the submarket dummies and the coordinates. The other explanatory variables do not seem to suffer from multicollinearity problems.

By using the estimated parameters concerning the monthly time dummies, an apartment price index for Stockholm is constructed. Figure 2 below compares the monthly time dummy hedonic price index with the monthly arithmetic mean and median price per square meter indexes. For the whole time period, the arithmetic mean and median price per square amount to about 36,300 and 36,670 SEK, respectively. The median price index tends to track along or slightly above the arithmetic mean price index until September 2007; however, after a period in which the indexes alternately are over and under each other, the median price index tracks below the arithmetic mean price index from January 2008 and onwards, ending about 9 index point below the final arithmetic mean index value.

Apart from a few spikes in the two average price indexes, all three indexes tend to track each other well until the beginning of January 2008. Then for about 1.5 months, the hedonic index indicates price appreciation, while the two average indexes show move in the opposite direction. The gap that occurs during this time period persists, since the hedonic index tend to move in same direction as the other indexes until June 2009.

\footnotetext{
${ }^{9}$ See the discussion above concerning "Interpretation of dummy variables in a semi-logarithmic equation": when $\ln (y)$ is the dependent variable, a recommended way to compute the percentage difference in the predicted y when $x_{1}=1$ versus $x_{1}=0$ is given by $100 \cdot[\exp (b)-1]$ (e.g. Wooldridge 2006, p. 238).
} 
Figure 2. Arithmetic mean, median and hedonic price (with monthly time dummy variables) indexes.

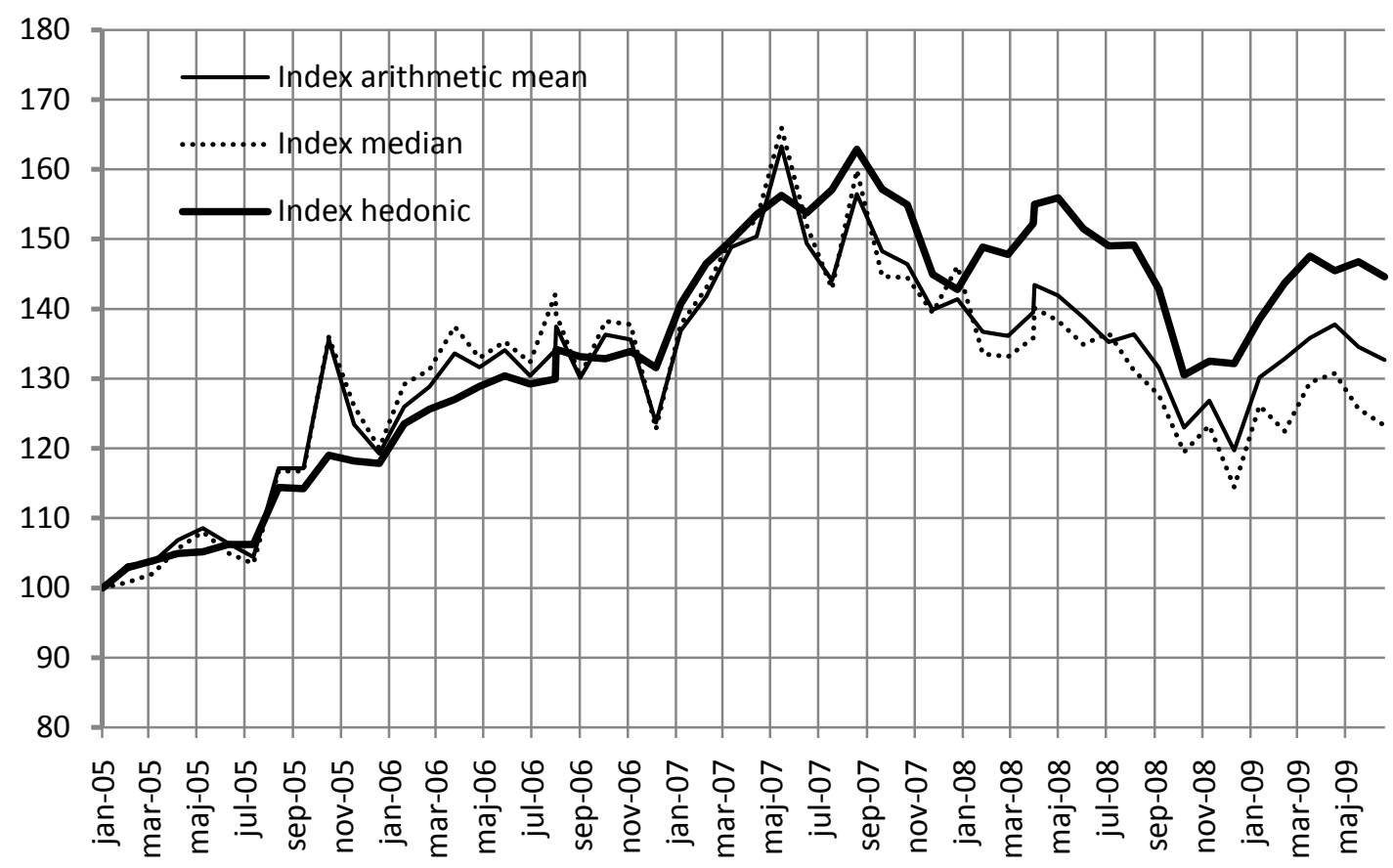

While the hedonic index has the highest time-weighted average monthly return (computed as the geometric mean return, see table 4 below), the median has the lowest. This also confirms that the hedonic index and the median index have the highest and lowest terminal index values respectively (144.61 and 123.30). Consequently, the choice of index might in an important way affect the economic performance of financial products (e.g. futures contracts) whose values are related to the performance of a specific apartment price index.

It can be observed that the hedonic price index is smoother compared to the other two indexes. Numerically the hedonic index has a lower standard deviation of monthly price changes (see table 4 below). Again, the choice of index might turn out to be important, since the standard deviation of price returns is a key parameter in the valuation of many derivative products.

Table 4. Index comparison for monthly percentage price changes.

\begin{tabular}{l|ccccc}
\hline Index & Mean & $\begin{array}{c}\text { Geometric } \\
\text { mean }\end{array}$ & $\begin{array}{c}\text { Standard } \\
\text { deviation }\end{array}$ & Minimum & Maximum \\
\hline Hedonic & 0.74 & 0.70 & 2.95 & -8.62 & 7.74 \\
Arithmetic mean & 0.66 & 0.54 & 5.13 & -8.99 & 15.79 \\
Median & 0.57 & 0.40 & 6.06 & -10.92 & 16.43 \\
\hline
\end{tabular}


When we estimate the hedonic index model described above, we assume that the implicit prices concerning the apartment and neighbourhood attributes are constant over time. Of course, that may be a too strong assumption to make. In order to test for constant implicit prices, we have estimated a variant of moving window regression by estimating the hedonic model in a oneyear time span sliding over time. This method resembles Mark and Goldberg (1984) approach that they call "Consecutive Years Aggregations with Time Dummy Variables" (p. 36), as well as Páez and Long (2008) approach with moving windows in space. ${ }^{10}$ The first estimation uses the transactions in January 2005 to December 2005, the second estimation uses transactions from February 2005 to January 2006, and so on, until the final $\left(43^{\text {rd }}\right)$ estimation that uses transactions from July 2008 to June 2009. Hence, instead of estimating one hedonic price equation for the time period January 2005 to June 2009, we now estimate 43 models. We have used the same bundle of characteristics in all equations and the same functional form. In the table below are four of these regression results presented.

The estimated coefficients in table 5 below indicate that implicit prices tend to change over time. For example, the importance of size seems to be less 2008 compared to 2005. Even the magnitude of the estimate concerning number of rooms is lower. The results indicate that the monthly fee has a lower impact on the prices today compared to three years ago. The depreciation rates seem to be relatively constant over the years, but the premium for new apartments is higher today than 2005. All of this indicates that the implicit assumption about constant hedonic prices over time seems not to be valid.

${ }^{10}$ In time-series analysis, this method is typically referred to as rolling windows regression, see Yaffee (2007). 
Table 5. Regression result for transactions in year 2005, 2006, 2007 and 2008 respectively.

\begin{tabular}{|c|c|c|c|c|}
\hline Variable & $\begin{array}{c}\text { Coefficient } \\
2005\end{array}$ & $\begin{array}{c}\text { Coefficient } \\
2006\end{array}$ & $\begin{array}{c}\text { Coefficient } \\
2007\end{array}$ & $\begin{array}{c}\text { Coefficient } \\
2008\end{array}$ \\
\hline Constant & $\begin{array}{c}-170.0451 \\
(-3.64)\end{array}$ & $\begin{array}{c}-139.5126 \\
(-6.00)\end{array}$ & $\begin{array}{c}30.8081 \\
(0.77)\end{array}$ & $\begin{array}{c}-122.3186 \\
(-3.51)\end{array}$ \\
\hline Living area & $\begin{array}{c}.9769 \\
(62.26)\end{array}$ & $\begin{array}{c}.9195 \\
(53.30)\end{array}$ & $\begin{array}{c}.8650 \\
(38.74)\end{array}$ & $\begin{array}{c}.8373 \\
(39.13)\end{array}$ \\
\hline Rooms & $\begin{array}{c}.1325 \\
(11.92)\end{array}$ & $\begin{array}{c}.1578 \\
(17.33)\end{array}$ & $\begin{array}{l}.1187 \\
(11.35)\end{array}$ & $\begin{array}{l}.0946 \\
(9.64)\end{array}$ \\
\hline Fee & $\begin{array}{c}-.2752 \\
(-23.02)\end{array}$ & $\begin{array}{c}-.2274 \\
(-11.68)\end{array}$ & $\begin{array}{l}-.1796 \\
(-6.24)\end{array}$ & $\begin{array}{l}-.1663 \\
(-6.65)\end{array}$ \\
\hline Balc & $\begin{array}{l}.0113 \\
(1.27)\end{array}$ & $\begin{array}{l}.0259 \\
(3.27)\end{array}$ & $\begin{array}{l}.0130 \\
(1.70)\end{array}$ & $\begin{array}{l}.0153 \\
(1.95)\end{array}$ \\
\hline First & $\begin{array}{c}0.0056 \\
(0.66)\end{array}$ & $\begin{array}{l}-.0100 \\
(-1.27)\end{array}$ & $\begin{array}{l}-.0173 \\
(-2.24)\end{array}$ & $\begin{array}{l}-.0183 \\
(-2.38)\end{array}$ \\
\hline Top & $\begin{array}{c}0.0226 \\
2.98)\end{array}$ & $\begin{array}{l}.0238 \\
(3.48)\end{array}$ & $\begin{array}{l}.0155 \\
(2.14)\end{array}$ & $\begin{array}{l}.0287 \\
(3.91)\end{array}$ \\
\hline Byear1 & $\begin{array}{l}.0767 \\
(6.29)\end{array}$ & $\begin{array}{l}.0382 \\
(4.02)\end{array}$ & $\begin{array}{l}.0440 \\
(4.15)\end{array}$ & $\begin{array}{l}.0494 \\
(4.33)\end{array}$ \\
\hline Byear2 & $\begin{array}{l}.0393 \\
(4.63)\end{array}$ & $\begin{array}{l}.0054 \\
(0.81)\end{array}$ & $\begin{array}{l}.0118 \\
(1.58)\end{array}$ & $\begin{array}{l}.0137 \\
(1.89)\end{array}$ \\
\hline Byear3 & $\begin{array}{l}-.0005 \\
(-0.05)\end{array}$ & $\begin{array}{l}-.0176 \\
(-2.17)\end{array}$ & $\begin{array}{l}-.0224 \\
(-2.47)\end{array}$ & $\begin{array}{l}-.0163 \\
(-1.90)\end{array}$ \\
\hline Byear4 & $\begin{array}{l}-.1200 \\
(-9.16)\end{array}$ & $\begin{array}{c}-.1339 \\
(-11.08)\end{array}$ & $\begin{array}{l}-.1262 \\
(-9.44)\end{array}$ & $\begin{array}{c}-.1875 \\
(-13.98)\end{array}$ \\
\hline Byear5 & $\begin{array}{l}-.1427 \\
(-7.16)\end{array}$ & $\begin{array}{c}-0.1436 \\
(-9.09)\end{array}$ & $\begin{array}{l}-.1459 \\
(-8.16)\end{array}$ & $\begin{array}{l}-.1425 \\
(-9.61)\end{array}$ \\
\hline New & $\begin{array}{l}-.0131 \\
(-0.24)\end{array}$ & $\begin{array}{l}.0454 \\
(2.47)\end{array}$ & $\begin{array}{l}-.0328 \\
(-1.96)\end{array}$ & $\begin{array}{l}.0886 \\
(6.10)\end{array}$ \\
\hline Elev*Floor & $\begin{array}{l}.0028 \\
(0.75)\end{array}$ & $\begin{array}{l}.0107 \\
(3.30)\end{array}$ & $\begin{array}{l}.0137 \\
(3.49)\end{array}$ & $\begin{array}{l}.0213 \\
(4.97)\end{array}$ \\
\hline Elev & $\begin{array}{l}-.0212 \\
(-2.00)\end{array}$ & $\begin{array}{l}-.0248 \\
(-3.33)\end{array}$ & $\begin{array}{l}-.0561 \\
(-5.13)\end{array}$ & $\begin{array}{l}-.0771 \\
(-6.59)\end{array}$ \\
\hline Dist & $\begin{array}{c}-.1887 \\
(-12.70)\end{array}$ & $\begin{array}{c}-.1805 \\
(-14.91)\end{array}$ & $\begin{array}{c}-.2247 \\
(-14.03)\end{array}$ & $\begin{array}{c}-.2264 \\
(-14.18)\end{array}$ \\
\hline $\begin{array}{l}\text { Number of } \\
\text { observations } \\
\mathrm{R}^{2} \text {-adj }\end{array}$ & $\begin{array}{l}5,613 \\
0.87\end{array}$ & 8,653 & 7,327 & 7,544 \\
\hline & \multicolumn{4}{|c|}{$\begin{array}{c}\text { Average home characteristics } \\
\text { Arithmetic mean (median) }\end{array}$} \\
\hline Living area & $69.62(67)$ & $68.41(66)$ & $69.01(66)$ & $68.26(66)$ \\
\hline Rooms & $2.55(2)$ & $2.51(2)$ & $2.53(2)$ & $2.52(2)$ \\
\hline Fee (Sek/month) & $3,429(3,169)$ & $3,469(3,163)$ & $3,598(3,219)$ & $3,502(3,273)$ \\
\hline $\begin{array}{l}\text { Note: All continuol } \\
\text { the variables X- an } \\
\text { distance variable ar } \\
\text { we do not have acc } \\
\text { alternative to drop } \\
\text { variables that indic } \\
\text { sub-markets dumm } \\
\text { within brackets. }\end{array}$ & $\begin{array}{l}\text { ariables are tran } \\
\text { coordinates, N } \\
\text { ne NE, NW, an } \\
\text { to information } \\
\text { the observatic } \\
\text { vhen we lack su }\end{array}$ & $\begin{array}{l}\text { led (natural log } \\
\mathrm{N} \text {, and SW, as } \\
\text { variables are } \mathrm{r} \\
\text { elevator, balc } \\
\text { om the analys } \\
\text { formation. The }\end{array}$ & $\begin{array}{l}\text { a). The coeffici } \\
\text { as the interactic } \\
\text { own in the table } \\
\text { loor level and } \\
\text { e have include } \\
\text { icient estimates }\end{array}$ & $\begin{array}{l}\text { estimates concer } \\
\text { ariables betweer } \\
\text { or many transac } \\
\text { ber of floors. A } \\
\text { number of dur } \\
\text { cerning the time }\end{array}$ \\
\hline
\end{tabular}


For the construction of monthly MWR indexes, we again estimate monthly time dummies. Every time new data (i.e. a new month's transactions) is added, we estimate a new index number that is based on transactions eleven months prior to the new month plus the new month. At the same time, all old index numbers will be revised ${ }^{11}$. The monthly index number will be revised eleven times. Hence two different types of MWR indexes can be estimated. Figure 3 below depicts them besides the full sample (aggregated) hedonic index. The index labeled MWR-First, is based on the first estimation of each of the monthly index numbers. The index MWR-Last is based on the final revision of each of the monthly index numbers. Despite that the implicit prices for a number of individual explanatory variables seem to change over time (see table 5 above), all three indexes tend to track each other very closely.

Figure 3. MWR-first, MWR-Final, and aggregated hedonic price indexes.

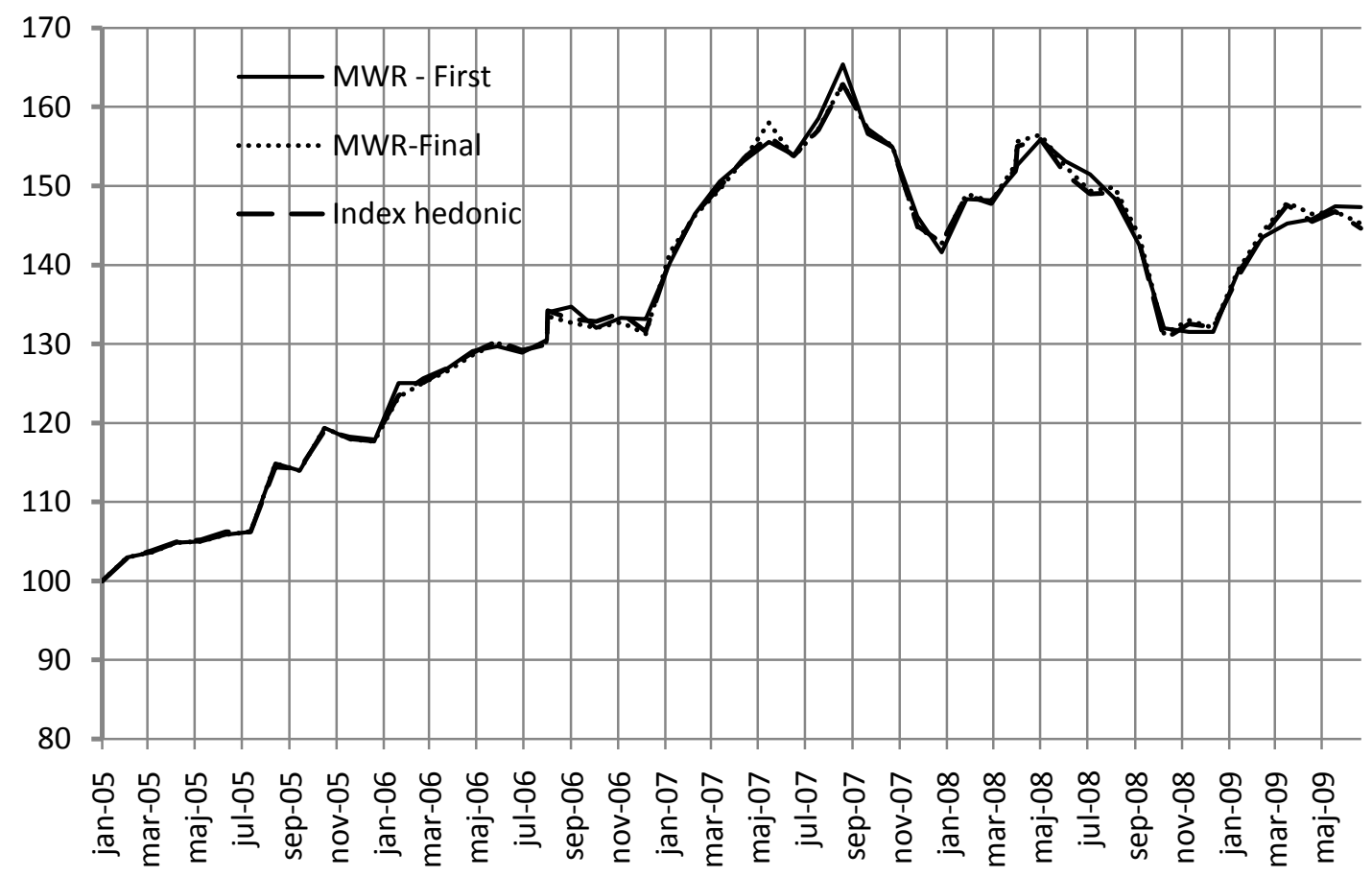

\section{Model selection with out-of-sample test}

Both figures 3 above, as well as the obtained values of adjusted R-squared (around 0.86-0.88 for the aggregated hedonic equation as well as for each of the 43 MWR equations) indicate that the three indexes seem to track each other very closely, making it difficult to decide on which of the three index methods is the most suitable. In order to choose the most suitable model

\footnotetext{
${ }^{11}$ Even in the full sample hedonic model above, we obtain revised index numbers each time observations from new time periods are added to the sample.
} 
among several competing models, statisticians and econometricians have developed several model selection statistics. In this article, we make an out-of-sample test by computing the root mean squared error (RMSE), which essentially is the sample standard deviation of the prediction (or forecast) errors. According to this out-of-sample test, the most suitable regression model is the one with the smallest out-of-sample RMSE (see e.g. Wooldridge, 2009). We use 80 percent of the observations (randomly sampled) to estimate the parameters in our model, and keep 20 percent for out-of-sample forecasting. The results of the RMSE-test, shown in table 6 below, indicate that the differences between the methods are very small. But is seems that the moving windows regression approaches are preferred to the aggregated hedonic approach, although the difference in RMSE might not be statistically significant.

Table 6. Out-of-sample RMSE comparisons of MWR-first, MWR-Final, and aggregated hedonic price indexes

\begin{tabular}{l|cc}
\hline Index & RMSE & $\begin{array}{c}\text { RMSE } \\
\text { Mean price }\end{array}$ \\
\hline MWR-first & 422,800 & $19.99 \%$ \\
MWR-Final & 422,500 & $19.98 \%$ \\
Hedonic & 439,700 & $20.79 \%$ \\
\hline
\end{tabular}

\section{Laspeyres and Paasche index in a MWR framework}

As noted above, with access to large number of observations in each time period (i.e each month in our application), it is possible to estimate a hedonic equation for each period. Then Laspeyres or Paasche index may be constructed by predicting the price of a standard home using the initial (base period) or final period average house and neighborhood characteristics, respectively. Finally it is possible to construct a Fisher ideal index.

We have not used this methodology, since the number of observations is limited in each month (that is the length the periods we apply). Instead we use the above described moving window regression approach to allow for using observations from each month-by-month sliding 12 month period. For each moving windows regression we then predict the period-by-period prices, using either the initial period (Jan 2005 - Dec 2005) or last period (Jul 2008 - Jun 2009) average home characteristics, obtaining MWR Laspeyres or Paasche index, respectively.

As figure 4 below illustrates, the three indexes are almost identical. As noted in figure 3 above, there is a small difference between the MWR indexes and the aggregated hedonic index, due to differences implicit prices and home characteristics. By controlling for home characteristics (i.e. Laspeyres or Paasche), figure 4 illustrates that the difference between the indexes become negligible. That is, the implicit prices are very robust over time. One reason could be that the 
time period we investigate is rather short (January 2005 to July 2009). However, for longer time periods, preferences and therefore willingness to pay for different home characteristics may change. Furthermore, the average apartment characteristics are also very similar as the bottom rows of table 5 illustrate: the average size of living area, number of rooms, and monthly fee, do not change significantly from year 2005 to $2008 .^{12}$

Figure 4. Aggregated hedonic price, MWR Laspeyres, and MWR Paasche indexes.

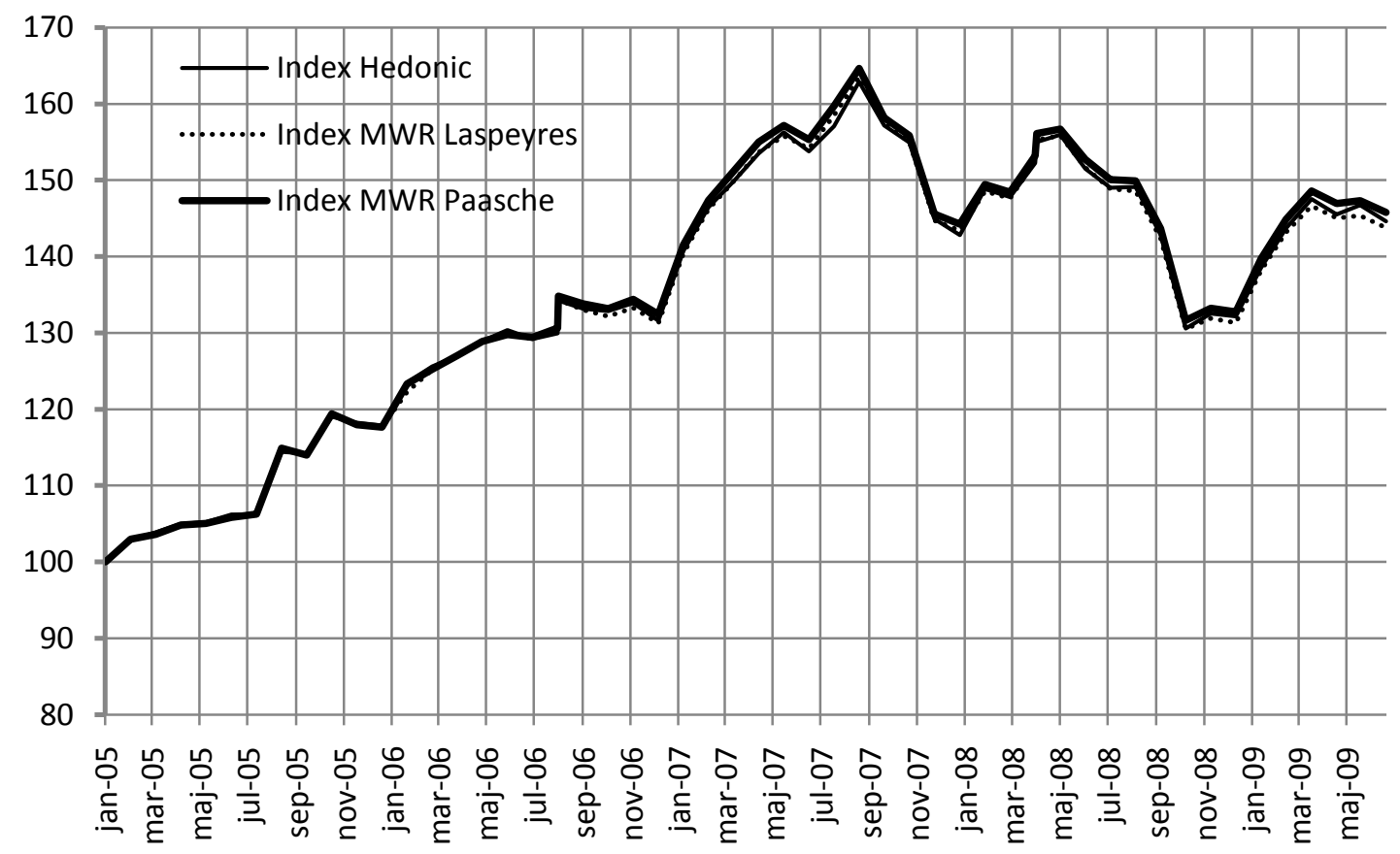

\section{Spatial hedonic price index}

There is no doubt that spatial dependence is present. The question is how well our fixed spatial effects and the distance variables capture the spatial dependence. We have utilized Moran's I in order to test for spatial correlation in the residuals of the regression models and used a moving window of 6 months. The spatial weight matrix is defined by the 10 closest neighbours (based on Euclidian distance). The weight matrix is normalized to have row-sums of unity.

Some of the apartments are located in the same property; hence, some apartments have zero distance to each other even though it is not the same apartments. The hypothesis is that these apartments have a large effect on the price on each other, but as the distance is zero, they will

\footnotetext{
${ }^{12} \mathrm{We}$ also compute a MWR version of the Fisher ideal index as the geometric mean of the MWR Laspeyres and MWR Paasche indexes. As expected, the MWR Fisher ideal index tracks the aggregated hedonic index very closely.
} 
seemingly have no effect at all. In order to come around this problem, all coordinates have been assigned, at random, a small number so that no distances are equal to zero.

Unfortunately the test shows that spatial correlation is present to a large extent. The Moran's I statistics is on average 52.73 (with the range of 32). In other words, we can reject the hypothesis of no spatial correlation (critical value 1.96).

The question is if the apartment price index is affected. Both the spatial regression models are estimated as moving window regression, that is, we have estimated two spatial moving window regression models: one spatial error model (SEMWR), and one spatial autocorrelation model (SAMWR). In this case we have limited the windows to be only six months, justified by computational reasons and that it is more likely that only sales close in time should have an impact on the price for an individual apartment. Below in figure 5, the aggregated hedonic price index is illustrated together with the two spatial regression indexes.

Figure 5. Aggregated hedonic (OLS), SEMWR and SAMWR estimated price index series.

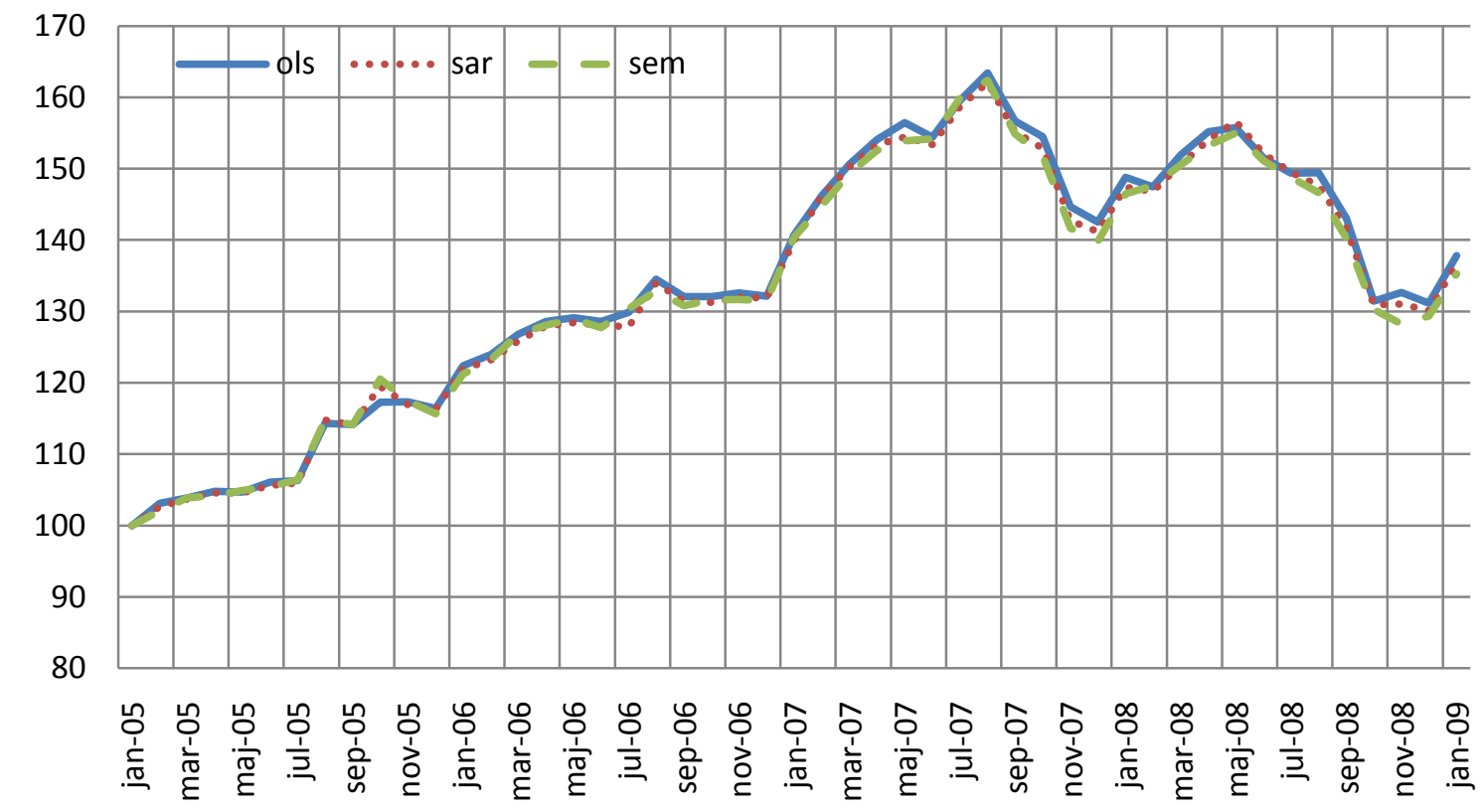

Although there is a presence of spatial dependency in our hedonic models, this seems not to spill over to the price indexes, as figure 4 illustrates. Indeed, the differences between the aggregated index (labelled OLS in table above), the SEMWR index, and the SAMWR index, seem not to be statistically significant. 


\section{Updating the index}

In order to analyze how the coefficients evolve over time, we estimate the coefficients as soon as transactions are available. Once new transactions are accessible, we re-estimate the coefficients, with additional number of observations. In most cases, it takes about one and a half month to get access to all transaction in a given month. The first transactions are observable after the first week of the month. In the figure 6 below, the coefficients and standard deviations for December 2008 and January 2009 presented. They are compared with the inflow of transactions.

Figure 6. Coefficients, standard deviations and number of transactions.

December, 2008
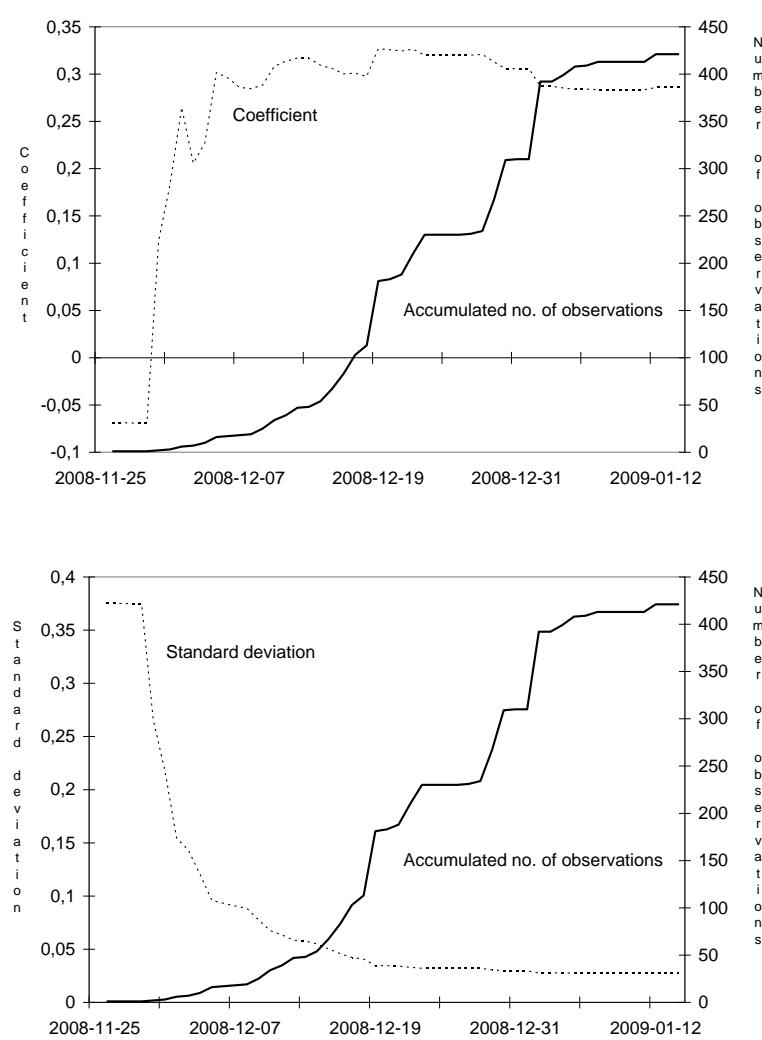

January, 2009
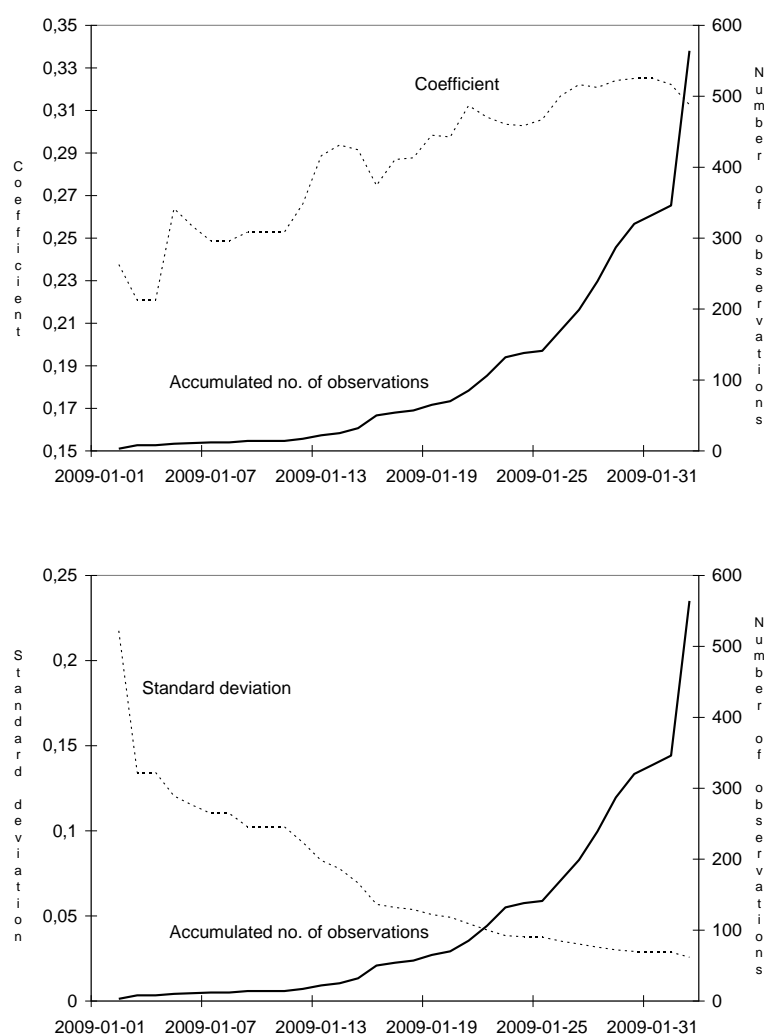

In both cases, the coefficients can be estimated with some accuracy relatively early. At the end of the month, when around 100-200 observations are available, the coefficients can be estimated with high exactness. The precision is getting higher and higher as more information is included in the model. 


\section{Summary and conclusions}

Academicians have developed and discussed many different methodologies to construct home price indexes in order to track home price movements as accurately as possible. Although average (arithmetic mean or median) price indexes are simple to compute, they cannot take into account that homes are heterogeneous goods. Since the composition of homes sold may vary from one period to another period, it is necessary to construct quality-adjusted home price indexes. Having access to the most recent sales information is yet another challenge that producers of home price indexes face. Many times index producers only have access to data that pairs sales prices with moving-in or deed dates. However, in order to avoid problems with time lags, index producers should use data that pairs sales prices with contract dates.

The objective of this article is to contribute to the literature on the production of reliable apartment price indexes. We develop a number of alternative monthly quality-adjusted price indexes for condominiums (housing cooperative apartments) based on a unique dataset covering sales in the whole of Stockholm municipality from January 2005 to June 2009. This data set contains both information about a number of important characteristics of the sold dwellings, geographical and locational attributes, as well as the dates when sales contract were signed, and not the transaction dates.

First, we estimate an aggregated hedonic equation with monthly time dummy variables, and compare this index with arithmetic mean and median price indexes. Although the three indexes basically show similar price trends, the monthly index figures differ in a significant way. The hedonic index is smoothed compared to the average price indexes, and therefore has a lower standard deviation of monthly price changes. This finding may be important, since the standard deviation of price returns is a key parameter in the valuation of different financial and insurance products.

Although an aggregated hedonic model has attractive features as compared to simple mean and median price indexes, the assumption that the implicit prices do not change over time may not be valid. Therefore, we estimate hedonic moving window regression indexes, in order to test whether the assumption of constant implicit prices over time is reasonable or not. Our results show that the difference between the aggregated hedonic equation index and the moving windows regression index models is very small. This result may be explained by the short time period (4.5 years) we consider in this paper. This fact might also explain why the moving windows regression versions of Laspeyres and Paasche indexes, in which we use the initial and final 12-month period quantities as weights (i.e. initial and final year "standard home"), yield indexes that are similar to the aggregated hedonic index. However, as times goes by, implicit 
prices as well as the characteristics of the "standard home" might change significantly, and therefore it may be important to further develop methods that consider these factors.

Although the hedonic approaches we develop in this paper seem to be promising, we must do more work in order to further improve the price indexes. First of all, the quality of the data on many of the attributes should be better. Currently many observations either lack relevant information about important home attributes as well as location and neighbourhood characteristics. With better information, we increase our chances to use more observations when we estimate different equations. Next, more research is needed in order to gain a better insight into the art of specifying the functional form of the hedonic equation. Naturally, this challenge is closely related to the problem of collecting data on relevant attributes (see e.g. Case et al., 1991). As we face a large number of competing index methodologies and models, the issue of model selection methods is yet another interesting research area. To conclude, we argue that we in this paper have made important contributions concerning the issue of improving price indexes for apartments. However, there is still room for more research as well as hands-on suggestions needed to improve data collection. Indeed, without good data quality, even the best model can yield highly biased indexes. 


\section{References}

Anselin, L. (1988). Spatial Econometrics: Method and Models. Dordrecht: Kluwer Academic Publishers.

Bourassa, S.C., Hoesli, M. and Sun, J. (2006). A simple alternative house price index method. Journal of Housing Economics, Vol.15, 80-97.

Can, A. and Megbolugbe, I. (1997). Spatial dependence and house price index construction. Journal of Real Estate Economics. Vol.14, 203-222.

Case, K.E. and Schiller, R.J. (1987). Prices of Single Family Home Since 1970: New Indexes for Four Cities. New England Economic Review, 45-56.

Case, B., Pollakowski, H.O. and Wachter, S.M. (1991). On Choosing Among House Price Index Methodologies. AREUEA Journal, Vol. 19(3), 286-307.

Case, K.E., Shiller, R.J. and Weiss, A.N. (1993). Index-based futures and options markets in real estate. Journal of Portfolio Management, Vol. 19(2), 83-92.

Clapham, E., Englund, P., Quigley, J. and Redfearn, C. (2006). Revistiting the Past and Settling the Score: Index Revision for House Price Derivatives. Real Estate Economic, Vol.34(2), $275-302$.

Deng, Y. and Quigley, J. M. (2008). Index revision, Price Risk, and the Market for House Price Derivatives. Journal of Real Estate Finance and Economics, Vol.37(3), 191-209.

Des Rosiers, F., Lagana, A. and Thériault, M. (2001) Size and proximity effects of primary schools on surrounding house values. Journal of Property Research, 18(2), p. 149-168.

Diewert, E. (2007). The Paris OECD-IMF Workshop on Real Estate Price Indexes: Conclusions and future Directions. Held in Paris, November 6-7, 2006.

Dubin, R. (1998). Spatial Autocorrelation: A Primer. Journal of Housing Economics. Vol 7(4), December 1998, 304-327

Englund, P., Hwang, M., Quigley, J.M. (2002). Hedging housing risk. Journal of Real Estate Finance and Economics, 24 (1-2), 167-200.

Englund, P., Quigley, J.M. and Redfearn, C.L. (1998). Improved price indexes for real estate: measuring the course of Swedish housing prices. Journal of Urban Economics, Vol.44(2), 171-196.

Englund, P. (2009). Trading on house price risk, Index derivatives and home equity insurance. Unpublished manuscript.

Galster, G., P. Tatian and K. Pettit (2004). Supportive Housing and Neighborhood Property Value Externalities. Land Economics, Vol.80(1), 33-54.

Garderen, K. J. Van and Shah, C. (2002). Exact interpretation of dummy variables in semilogarithmic equations. Econometrics Journal, Vol.5, 149-159.

Giles, D.E.A. (1982). The Interpretation of Dummy Variables in Semilogarithmic Equations Unbiased estimation. Economic Letters, Vol.10, 77-79.

Goldberger, A. (1968). The Interpretation and Estimation of Cobb-Douglas Functions, American Economic Review. Vol.35 (3-4), 464-472. 
Hansen, J. (2006). Australian House Prices: A Comparison of Hedonic and Repeat-sales Measures. Research Discussion Paper 2006-03, Reserve Bank of Australia.

Halvorsen, R. and R. Palmquist (1980). The interpretation of dummy variables in semilogarithmic equations. American Economic Review 70: 474-475.

Halvorsen, R., and Pollakowski, H. (1981). Choice of Functional Form for Hedonic Price Equations, Journal of Urban Economics. 10, 37-49.

Hill, R. J. and Melser, D. (2008). Hedonic Imputation and the Price Index Problem: an Application to Housing. Economic Inquiry. Vol. 46(4), 593-609.

Hoesli, M. and MacGregor, B.D. (2000). Property Investment: Principles and Practice of Portfolio Management. Pearson Education Limited, Essex, England.

Janssen, C. and Söderberg, B. (1999) Estimating Market Prices and Assessed Values for Income Properties. Urban Studies, 36(2), p. 359-376.

Kennedy, P.E. (1981). Estimation with correctly interpreted dummy variables in semilogarithmic equations, American Economic Review, Vol.71, p. 801.

Kryvobokow, M. and Wilhelmsson, M. (2007). Analyzing location attributes with hedonic model for apartment prices in Donetsk, Ukraine. International Journal of Strategic Property Management, Vol.11, 157-178.

Mark, J. H. and Goldberg, M.A. (1983). Alternative Housing Price Indices: An Evaluation. Real Estate Economics, Vol.12(1), 30-49.

Maurer, R., Pitzer, M. and Sebastian, S. (2004). Hedonic price indices for the Paris housing market. Allgemeines Statistisches Archiv, Vol 88, 303-326.

Meese, R. and Wallace, N. (1997). The Construction of Residential House Price Indices: A Comparison of Repeat-Sales, Hedonic-Regression, and Hybrid Approaches. Journal of Real Estate Finance and Economics, Vol.14, 51-73.

Meese, R. and Wallace, N. (2003). Nonparametric Estimation of Dynamic Hedonic Price Models and the Construction of Residential Housing Price Indices. Real Estate Economics, Vol.19(3), 308-332.

Páez, A. and Long, F. (2008). Moving Window Approaches for hedonic prices estimation: An Empirical Comparison of Modelling Techniques. Urban Studies, Vol. 45(8), 1565-1581.

Pakes, A. (2003). A reconciliation of Hedonic Price Indexes with an Application to PC's. American Economic Review, 93: 1578-96.

Palmquist, R.B. (1980). Alternative Techniques for Developing Real Estate Indexes. The Review of Economics and Statistics, Vol.62(3), 442-448.

Seiler, M. J., Bond, M. T. and Seiler, V. L. (2001). The Impact of World Class Great Lakes Water Views on residential Property Values. The Appraisal Journal, LXIX(3), p. 287-295.

Shimizi, C. and Nishimura, K.G. (2007). Pricing Strycture in Tokyo Metropolitan Lan Markets and its Structural Changes: Pre-bubble, Bubble, and Post-bubble Periods. Journal of Real Estate Economics, Vol.35, 475-496.

Song, S., Young, M. and Hargreaves, B. (2009). Issues in measuring a monthly house price index in New Zealand. Journal of Housing Economics, Forthcoming. 
Wilhelmsson, M. (2002a). Spatial Models in Real Estate Economics. Housing, Theory and Society Vol.19. 92-101.

Wilhelmsson, M. (2008). Evidence of Buyer Bargaining Power in the Stockholm Residential Real Estate Market. Journal of Real Estate Research.Vol.30(4), 275-299.

Wilhelmsson, M. (2009). Construction and Updating of Property Price Index Series: The Case of Segmented Markets in Stockholm. Property Management, Vol.27(2), 119-137.

Wooldridge, J.M. (2006). Introductory Econometrics - A modern approach. Thomson, SouthWestern, Mason, USA.

Yaffee, R.A. (2007). A review of Stata versions 9 and 10 time series and forecasting capability. Journal of Statistical Software. Vol.23(1).1-18. 